\title{
Dog: A Friendly Pathway to Zoonoses
}

\author{
A. Pathak* and K. Kaphle \\ Institute of Agriculture and Animal Science, Tribhuvan University, Paklihawa, Rupandehi, Nepal. \\ *Corresponding author: pathakanis@gmail.com
}

\begin{abstract}
Canis lupus familaris (Dog); a companion animal or even considered man's best friend is believed to have been living in harmony with humans since thousands of years. Recent discovery in Chauvet cave in France: foot print of 8-year-old boy alongside the paw print is believed to have been dated back to Paleolithic period. Reports even suggest that pet owners are less prone to high cholesterol and high blood pressure than the non-pet owners. However, dogs are also the major reservoir of various zoonotic infections. Several bacterial, viral or protozoal diseases that occur in human are transmitted from the dogs. Such diseases are known as zoonotic diseases. These diseases can be transmitted by simple contact with the infected dogs or by infected urine or feces, saliva or aerosols. Viral infections such as rabies and noro virus, bacterial infection such as pasteurellosis, salmonellosis, campylobacteriosis, leptospirosis and Methicillin-Resistant Staphylococcus aureus (MRSA) infections and protozoal infections like ancylostomiasis, toxocariasis and Dipylidium caninum infection are the most common zoonotic infections. This paper focuses on these diseases including information on signs and symptoms, mode of transmission and prevention of these diseases. As much as these infections are concerned, knowledge boosting of the pet owners regarding zoonotic disease along with proper hygiene and good sanitation practices could considerably decline the rate of zoonoses transmission and consequences.
\end{abstract}

Keywords: Canine, Infections, Zoonoses

\section{INTRODUCTION}

The bond between humans and dog is believed to have begun since ten thousand years (World Health Organization, 1990). However, the recent discovery of 8-year-old boy and paw print alongside him in the Chauvet cave of France, which is believed to be from the Paleolithic period; suggests that the relationship between the two species existed for thousand years back and these two species have been living together on harmony mutually benefitting each other's existence. Pet animals such as dogs and cats have become a fundamental part of families residing on every corner of the world. Furthermore, it has been reported that, pet owners are less prone to high cholesterol and high blood pressure than the non-pet owners (Headey and Krause, 1999).

Along with the pet animals that stay with the humans in their homes, the population of free roaming dogs, commonly known as stray dogs is also increasing in an alarming rate. Street dogs appear to aggregate near slaughter house and garbage piles which forms a hub for breeding and transmitting diseases (Nasution, 2015). With the ever increasing population density in the developing countries, uncontrolled population of stray dogs along with lack of veterinary 
knowledge and zoonotic awareness elevates the risks of disease transmission (Traub, Robertson, Irwin, Mencke, and Thompson, 2005).

Although these animals provide pivotal advantages to our society, adopting a pet may manifest several health hazards to the owners. Many bacterial, viral or parasitic infections that may occur in dogs have a high zoonotic significance and may transmit to the humans (Plaut, 1996).

\section{ZOONOTIC DISEASES IN DOGS.}

\section{Viral Zoonotic Diseases.}

\section{Rabies}

Rabies is caused by the single stranded DNA virus which belongs to Rhabdoviridae family. It is an ancient disease which causes high mortality rate both in human and animal population (Ghasemzadeh and Namazi, 2015). World Health Organization has reported that 30000 to 70000 deaths annually throughout the world because of rabies infection (Krebs, Mandel, Swerdlow, and Rupprecht, 2004). The major reservoir of rabies infection are dogs. Besides dogs the animals like racoons, bats and foxes also harbor the virus and are major cause of infection in developed countries (Tang, Luo, and Zhang, 2005). Depending on the site of the wound and amount of virus induced, incubation period of the disease ranges from 4 days to several years. Infected ones may manifest signs such as confusion, hydrophobia, hallucination, agitation and anxiety. If bitten by the suspected animals, post exposure prophylaxis with frequent dose of human rabies immunoglobulin (HRIG) within 14 days can prevent the disease (Lucas et.al., 2008).

\section{Noro Virus Infection}

This infection occurs due to heterogenous single stranded RNA virus which belongs to Caliciviridae family. The previous studies have suggested that, it is one of the leading cause of diarrheal diseases in humans of all age groups (Patel, Hall, Vinjé, and Parashar, 2009). Intestinal canal of dogs is primary affecting site of the virus thus are consequently seen in the feces of the infected dogs. Contaminated food or water is the main route of transmission of the virus to humans and can be controlled by strict hygiene maintenance and reduction of secondary outbreak propagation from human-to-human.

\section{Bacterial Zoonotic Diseases}

\section{Pasteurellosis}

Pasteurella are the gram-negative coccobacilli, which add up to the normal body microflora of upper respiratory tract of dogs and cats. Pasteurellosis can be transmitted directly and indirectly to humans both via dog or cat bites and sometimes even from their licks or scratches (Ghasemzadeh and Namazi, 2015). Primary infection occurs in soft tissues while secondary infection may affect bones, joints, brain and respiratory tract (Kristinsson and York, 2015). The infection can be treated by second and third generation cephalosporin, macrolides, fluoroquinolones, cotrimoxazole, and penicillin (Lloret et.al., 2013). 


\section{Salmonellosis}

Salmonella are anaerobic, gram-negative motile bacilli that develop in distal part of colon and mesenteric lymph nodes of the canine species and are responsible for causing Salmonellosis. Transmission in humans occurs through the fecal transmission route and manifests clinical signs like gastroenteritis, enteric fever, bacteremia and osteomyelitis. The most common signs of this disease in both the species viz dogs and humans are gastrointestinal signs; however, majority of these infection go unnoticed. Infected animal may shed the pathogen through feces for a period of 6 weeks and transmit them to other animals or individuals (Finley et.al., 2007). For the treatment of the infected animals and individuals, antibiotics including fluroquinolones, betalactams and macrolides are preferred (Leonard et.al., 2011).

\section{Campylobacteriosis}

Campylobacter, a gram-negative bacterium, causes campylobacteriosis. The most prevalent species include Campylobacter jejuni and Campylobacter coli. This microorganism resides in the gastrointestinal tract of many animals and hence acts as a prominent zoonotic agent. Incubation period varies from one day to a week at max. Common clinical signs include fever, vomiting, diarrhea and abdominal pain. Apart from this, bloody diarrhea may also be evident. There has been report of convulsion and seizures in some patients (Gazaigne et.al., 2008). Normally, campylobacter infection doesn't need any antimicrobial therapy. However, hydration should be considered for correction of electrolyte imbalance. In case of severe infections, antibiotics like fluoroquinolones, macrolides, or aminoglycosides should be considered (Ternhag, Asikainen, Giesecke, and Ekdahl, 2007).

\section{Leptospirosis}

Leptospirosis is caused by a spirochete bacteria Leptospira. Leptospirosis in humans is mostly transmitted by environmental factors including contaminated soil, water, urine or infected animal's tissue. Rodents play the role of major reservoirs for Leptospirosis; however, domestic animals including dogs also transmit leptospirosis in endemic regions (Moore et.al., 2006). The major pathway for leptospirosis transmission is direct contact of contaminated urine with the mucosal surfaces of eye, vagina, nose, mouth, or erosive lesions on the human body. Clinical signs are seen in the infected humans within 10 days of disease transmission [ranges from 2 to 26 days] (Sehgal, 2006).

Leptospirosis sometimes is asymptomatic whereas sometime is seen with variety of symptoms including nonproductive cough, headache, musculoskeletal pain, diarrhea, nausea, vomiting, alveolar hemorrhage and sometimes meningitis (World Health Organization, 2003). Usually antibiotics such as doxycycline, cefotaxime, penicillin, amoxicillin and ampicillin is used for Leptospirosis treatment (Kobayashi, 2001).

\section{Methicillin-Resistant Staphylococcus aureus (MRSA) Infection}

Staphylococcus aureus is a Gram-positive, round-shaped bacterium that is a member of the Firmicutes, and it is a usual member of the microbiota of the body, habitually found on the skin 
and upper respiratory tract. Otherwise harmless, they can sometime cause serious infections leading to sepsis resulting in death. Methicillin-resistant Staphylococcus aureus (MRSA) is a cause of staph infection which is burdensome during treatment as it is resistant to some antibiotics. It has been reported that the pathogen has been isolated from farm animals such as pigs, horses, cattle, cats and dogs. Among these animals, some believed that dogs and cats were the main reservoirs for transmission of MRSA by direct contact with their owners (Ghasemzadeh and Namazi, 2015). The infection probability exceeds more in immuno-compromised patients than the healthy ones. However, some evidences revealed that bacteria attack the healthy owners with infected pets (Iii, Rue, Wilckens, and Frassica, 2004; Va, Sahi, Suominen, and Va, 2005). With the advancement in the bacteria, traditional antibiotics are quite not efficient in treating the disease. Newer drugs including linezolid, daptomycin and vancomycin are effective in the treatment of MRSA infection (Morgan et.al., 2008).

\section{Parasitic Zoonotic Diseases}

\section{Ancylostomiasis}

Ancylostomiasis is caused by the Ancylostoma spp. mainly Ancylostomacanis. It is one of the most common hookworms of dogs. This parasite reach adulthood in humans and cause eosinophilic enteritis (Landmann and Prociv, 2003). After contact with the human host, the parasite enters the skin and reaches heart and lungs. Then by penetrating through the pulmonary alveoli, reach pharynx via bronchial tree and are swallowed. The parasite then reach the small intestine where they gets attached to the intestinal wall and cause huge blood loss in the hosts (Centers for Disease Control and Prevention, n.d.). The clinical signs of the disease include abdominal pain, colic or cramps, nausea, pyrexia, bloody stool, loss of appetite and itchy rash (Brooker, Bethony, and Hotez, 2004).

\section{Toxocariasis}

Toxocariasis is a zoonotic infection caused by the parasitic roundworms commonly found in the intestines of dogs. (Toxocara canis) Infection in humans are commonly mediated by the accidental ingestion of embryonated eggs present in the soil or contaminated food/water (OliartGuzmań et.al., 2014) or less frequently by meat ingestion from intermediate hosts (Choi et.al., 2012). Once the parasite enters the human host, the parasite reach circulation and gets distributed throughout the body. Majority of these cases go unnoticed: but in severe cases manifested by extensive larval migration:- signs like fever, eosinophilia, hepatomegaly, ocular symptoms, cardiac or pulmonary symptoms and sometimes even cerebral lesions are seen (Overgaauw, 1997).

\section{Dipylidium caninum infection}

Dipylidium caninum, occasionally found in humans, is a common tapeworm of dogs and cat. It's also known as "flea tapeworm", "cucumber tapeworm" and double pored tapeworm" (Centers for Disease Control and Prevention, 2019). The transmission of this parasite in dogs is mainly mediated by fleas, Ctenocephalides canis, C. felis along with dog biting louse, Trichodectes canis. Dogs accidently gets infected by ingesting the flea or lice (Soulsby, 1982). The infected 
dogs release the proglottids along with their feces in the environment and these eggs with proglottids gets consumed by flea larvae (Yasuda, Nishikawa, Ujihashi, and Watanabe, 1970). Though the parasite is not quite harmful in adult dogs, there may be some hemorrhages at the site of attachments resulting in enteritis and diarrhea (Soulsby, 1982). Accidental infection in humans occurs when the dog flea with parasite are swallowed. The infections of Dipylidium caninum is mostly reported in children (Narasimham et.al., 2013; Ramana, Rao, Rao, Mohanty, and Wilson, 2011). When the gravid proglottids pass through the anus, pruritus is seen in the infected host. Treatment of Dipylidium caninum can be successfully carried out on both cases of humans and animals (Saini, Gupta, Kasondra, Rakesh, and Latchumikanthan, 2016).

\section{Tackling Zoonotic Diseases in Dogs}

With the advancement of the medical industries different commercial vaccines are available in the pet owners and veterinarian's disposal for prevention of the diseases. However, to ensure disease prevention, strict protocol should be followed in dogs. The vaccination protocol is given below.

\begin{tabular}{|c|c|c|c|c|c|}
\hline S.N. & Vaccine & Type of Vaccine & Age & Booster & Repeat \\
\hline 1. & $\begin{array}{l}\text { Canine Distemper and } \\
\text { Measles virus }\end{array}$ & Modified live virus & 6-8 weeks & 12-16 weeks & Annual \\
\hline 2. & $\begin{array}{l}\text { Infectious Canine } \\
\text { Hepatitis Virus }\end{array}$ & $\begin{array}{l}\text { Modified live virus (CAV-1 } \\
\text { or CAV-2) or inactivated } \\
(\mathrm{CAV}-1) \text { vaccine }\end{array}$ & 6-8 weeks & 12-16 weeks & Annual \\
\hline 3. & Rabies Virus & $\begin{array}{l}\text { Modified Live vaccine } \\
\text { Inactivated virus }\end{array}$ & $\begin{array}{l}\text { 3-4 months } \\
3-4 \text { months }\end{array}$ & $\begin{array}{l}1 \text { year } \\
3-4 \text { weeks }\end{array}$ & $\begin{array}{l}3 \text { years } \\
\text { Annual }\end{array}$ \\
\hline 4. & Canine Leptospirosis & Killed bacteria (bacterin) & 9 weeks & 12-16 weeks & Annual \\
\hline 5. & Parvo Virus & Inactivated & 6-8 weeks & 12 weeks & Annual \\
\hline
\end{tabular}

(Source: Chakrabarti, 1993)

Infection can also be prevented by sanitation, hygiene and vaccination. Along with this cautious use of antibiotics in the farm animals should also be utilized. For the prevention of zoonotic disease and betterment of public health, veterinarians, physicians and public health agencies have varieties roles to play. Efficient communication between the veterinarians and physicians should be established to help estimate the risk of different zoonotic disease, properly educate pet owners and promptly diagnose zoonotic disease in animals and people (Lipton, Hopkins, Koehler, and Ronald, 2008).

\section{CONCLUSION}

Zoonotic diseases are those disease affecting both animals and humans and can be transferred either by pets or wildlife. The ever-increasing trend of pet rearing and huge number of stray dogs that coexist with human dwellings in the city area of developing nations bring about great quantity of dogs in and around our surroundings. With a dramatic number of canines around 
human population, the risk of dog-borne zoonoses are also increasing in an alarming rate. Dogs harbor different virus, bacterial and protozoal disease that have a very high zoonotic significance and in worst case scenario can be fatal. Moreover, dog transmitted parasitic infections causing different infections and affecting lives of billions of people often goes unnoticed (Macpherson, 2005).

Thus, to reduce these dog-borne zoonoses, the pet owners should be well informed. To tackle such infections several prophylactic and chemotherapeutic measures can be applied. It is recommended that the dog owners follow the vaccination protocol for the prevention of diseases. Along with this, strict sanitation and proper hygiene is to be maintained by the pet owners. As most of these pathogens gain entry in the dogs via feco-oral route, food hygiene must be addressed too. Raw meats should be completely avoided. And to avoid feco-oral transmission in humans, vegetables and food items should be properly washed before being cooked or eaten. If the knowledge level of pet owners about zoonotic disease and their treatment can be increased alongside the pet owning trend, then it will be safe to say that it would greatly reduce the prevalence of zoonoses in dog owners and common people.

\section{REFERENCES}

Brooker, S., Bethony, J., and Hotez, P. J. (2004). Human hookworm infection in the 21st century. Advances in Parasitology. https://doi.org/10.1016/S0065-308X (04)58004-1

Centers for Disease Control and Prevention. (n.d.). Hookworm. Retrieved from Global Health, Division of Parasitic Diseases and Malaria website: https:/www.cdc.gov/dpdx/hookworm/index.html

Centers for Disease Control and Prevention. (2019). Dipylidium caninum. Retrieved from Global Health, Division of Parasitic Diseases and Malaria website: https://www.cdc.gov/dpdx/dipylidium/index.html

Chakrabarti, A. (1993). A Textbook of Preventive Veterinary Medicine. Kalyani Publishers, New Delhi.

Choi, D., Lim, J. H., Choi, D. C., Lee, K. S., Paik, S. W., Kim, S. H., .. Huh, S. (2012).

Transmission of Toxocara canis via ingestion of raw cow liver: A cross-sectional study in healthy adults. Korean Journal of Parasitology, 50 (1), 23-27. https://doi.org/10.3347/kjp.2012.50.1.23

Finley, R., Ribble, C., Aramini, J., Vandermeer, M., Popa, M., Litman, M., and Reid-Smith, R. (2007). The risk of salmonellae shedding by dogs fed Salmonella-contaminated commerical raw food diets. Canadian Veterinary Journal, 48 (1), 69-75.

Gazaigne, L., Legrand, P., Renaud, B., Bourra, B., Taillandier, E., Brun-Buisson, C., and Lesprit, P. (2008). Campylobacter fetus bloodstream infection: Risk factors and clinical features. European Journal of Clinical Microbiology and Infectious Diseases, 27 (3), 185-189. https://doi.org/10.1007/s10096-007-0415-0

Ghasemzadeh, I., and Namazi, S. H. (2015). Review of bacterial and viral zoonotic infections transmitted by dogs. Journal of Medicine and Life, 8 (Spec Iss 4), 1-5. Retrieved from http:/www.ncbi.nlm.nih.gov/pubmed/28316698\%0Ahttp:/www.pubmedcentral.nih.gov/ articlerender.fcgi?artid=PMC5319273

Headey, B., and Krause, P. (1999). Health Benefits and Potential Budget Savings Due to Pets: Australian and German Survey Results. Australian Social Monitor, 2 (2), 37-41.

Iii, D. W. A., Rue, J. H., Wilckens, J. H., and Frassica, F. J. (2004). Stress fracture injury in 
young military men and women. 35, 806-816. https://doi.org/10.1016/j.bone.2004.05.014 Kobayashi, Y. (2001). Clinical observation and treatment of leptospirosis. Journal of Infection and Chemotherapy, 7 (2), 59-68.

Krebs, J. W., Mandel, E. J., Swerdlow, D. L., and Rupprecht, C. E. (2004). Rabies surveillance in the United States during 2003. Journal of the American Veterinary Medical Association, 225 (12), 1837-1849. Retrieved from http://www.ncbi.nlm.nih.gov/pubmed/15643834

Kristinsson, G., and York, N. (2015). Pasteurella multocida Infections. 28 (12).

Landmann, J. K., and Prociv, P. (2003). Experimental human infection with the dog hookworm. The Medical Journal of Australia, (178), 69-71.

Leonard, E. K., Pearl, D. L., Finley, R. L., Janecko, N., Peregrine, A. S., Reid-Smith, R. J., and Weese, J. S. (2011). Evaluation of pet-related management factors and the risk of Salmonella spp. carriage in pet dogs from volunteer households in Ontario (2005-2006). Zoonoses and Public Health, 58 (2), 140-149. https://doi.org/10.1111/j.18632378.2009.01320.x

Lipton, B. A., Hopkins, S. G., Koehler, J. E., and Ronald, F. (2008). Lipton-2008_survey of vet involvement in zoonotic disease prevention. 233 (8).

Lloret, A., Egberink, H., Addie, D., Belák, S., Boucraut-Baralon, C., Frymus, T., ... Horzinek, M. C. (2013). Pasteurella Multocida Infection in Cats: ABCD guidelines on prevention and management. Journal of Feline Medicine and Surgery, 15 (7), 570-572. https://doi.org/10.1177/1098612X13489215

Lucas, C. H. A., Pino, F. V., Baer, G., Morales, P. K., Cedillo, V. G., Blanco, M. A. L., and Avila, M. H. (2008). Rabies control in Mexico. Developments in Biologicals.

Macpherson, C. N. L. (2005). Human behaviour and the epidemiology of parasitic zoonoses. International Journal for Parasitology, 35 (11-12), 1319-1331.

https://doi.org/10.1016/j.ijpara.2005.06.004

Moore, G. E., Guptill, L. F., Glickman, N. W., Caldanaro, R. J., Aucoin, D., and Glickman, L. T. (2006). Canine leptospirosis, United States, 2002-2004. Emerging Infectious Diseases, 12 (3), 501-503. https://doi.org/10.3201/eid1203.050809

Morgan, M., Microbiology, M., Devon, R., Foundation, E., Trust, N. H. S., Lane, C., and Ex, D. (2008). Methicillin-resistant Staphylococcus aureus and animals : zoonosis or humanosis? (September), 1181-1187. https://doi.org/10.1093/jac/dkn405

Narasimham, M., Panda, P., Mohanty, I., Sahu, S., Padhi, S., and Dash, M. (2013). Dipylidium caninum infection in a child: A rare case report. Indian Journal of Medical Microbiology. https://doi.org/10.4103/0255-0857.108738

Oliart-Guzmań, H., Delfino, B. M., Martins, A. C., Mantovani, S. A. S., Braña, A. M., Pereira, T. M., ... Da Silva-Nunes, M. (2014). Epidemiology and control of child toxocariasis in the Western Brazilian Amazon - A population-based study. American Journal of Tropical Medicine and Hygiene. https://doi.org/10.4269/ajtmh.13-0506

Overgaauw, P. A. M. (1997). Aspects of Toxocara epidemiology: Toxocarosis in dogs and cats. Critical Reviews in Microbiology, 23 (3), 233-251. https://doi.org/10.3109/10408419709115138

Patel, M. M., Hall, A. J., Vinjé, J., and Parashar, U. D. (2009). Noroviruses: A comprehensive review. Journal of Clinical Virology, 44 (1), 1-8. https://doi.org/10.1016/j.jcv.2008.10.009

Plaut, M. (1996). Health Hazards to Humans Associated with Domestic Pets. Annual Review of 
Public Health, 17 (1), 221-245. https://doi.org/10.1146/annurev.publhealth.17.1.221

Ramana, K. V., Rao, S. D., Rao, R., Mohanty, S. K., and Wilson, C. G. (2011). Human dipylidiasis: A case report of Dipylidium canunum infection in teaching hospital at Karimnagar. Online Journal of Health and Allied Sciences, 10 (2), 1-2.

Saini, V. K., Gupta, S., Kasondra, A., Rakesh, R. L., and Latchumikanthan, A. (2016). Diagnosis and therapeutic management of Dipylidium caninum in dogs: a case report. Journal of Parasitic Diseases, 40 (4), 1426-1428. https://doi.org/10.1007/s12639-015-0706-9

Sehgal, S. C. (2006). Epidemiological patterns of leptospirosis. Indian Journal of Medical Microbiology., 24 (4), 310-311.

Soulsby, E. (1982). Helminths, arthropods and protozoa of domesticated animals (7th editio). Bailliere Tindall, London.

Tang, X., Luo, M., and Zhang, S. (2005). Pivotal Role of Dogs in Rabies. Emerging Infectious Diseases, 11 (12), 11-13.

Ternhag, A., Asikainen, T., Giesecke, J., and Ekdahl, K. (2007). A Meta-Analysis on the Effects 7of Antibiotic Treatment on Duration of Symptoms Caused by Infection with Campylobacter Species. Clinical Infectious Diseases, 44 (5), 696-700. https://doi.org/10.1086/509924

Traub, R. J., Robertson, I. D., Irwin, P. J., Mencke, N., and Thompson, R. C. A. A. (2005). Canine gastrointestinal parasitic zoonoses in India. Trends in Parasitology, 21 (1), 42-48. https://doi.org/10.1016/j.pt.2004.10.011

Va, V., Sahi, T., Suominen, H., and Va, M. J. (2005). Risk factors for clinical stress fractures in male military recruits : A prospective cohort study. 37, 267-273. https://doi.org/10.1016/j.bone.2005.04.016

World Health Organization. (1990). Guidelines for dog population management (World Society For The Protection Of Animals, Ed.). Geneva, Switzerland.

World Health Organization. (2003). Human leptospirosis: guidance for diagnosis, surveillance and control.

Yasuda, F., Nishikawa, H., Ujihashi, M., and Watanabe, S. (1970). Studies on the life-history of Dipylidium caninum (Linnaeus, 1758). II. The ecology of the mature proglottids and the cellophane-tape method of diagnosis based on the biological characteristics of the proglottids. Bull. Nippon Vet. Zootech Coll., 18, 122-128. 